\title{
Leukocyte-depleted terminal blood cardioplegia provides superior myocardial protective effects in association with myocardium-derived nitric oxide and peroxynitrite production for patients undergoing prolonged aortic crossclamping for more than 120 minutes
}

Yoshitaka Hayashi, MD, PhD

Yoshiki Sawa, MD, PhD

Naoto Fukuyama, MD, $\mathrm{PhD}^{\text {b }}$

Yuji Miyamoto, MD, $\mathrm{PhD}^{\mathrm{a}}$

Toshiki Takahashi, MD, PhD ${ }^{\mathrm{a}}$

Hiroe Nakazawa, MD, $\mathrm{PhD}^{\mathrm{b}}$

Hikaru Matsuda, MD, $\mathrm{PhD}^{\mathrm{a}}$

From the Department of Surgery, ${ }^{\text {a }}$ Course of Interventional Medicine (E1), Osaka University Graduate School of Medicine, Suita, Osaka, Japan, and Second Department of Physiology, ${ }^{\text {b }}$ Tokai University School of Medicine, Isehara, Kanagawa, Japan.

Presented in part at the First Asia Pacific Scientific Forum (supported by American Heart Association), Honolulu, Hawaii, April 23-26, 2002.

Received for publication Dec 25, 2002; revisions requested $\mathrm{Feb}$ 20, 2003; revisions received March 21, 2003; accepted for publication April 21, 2003.

Address for reprints: Yoshitaka Hayashi, MD, PhD, Department of Surgery, Course of Interventional Medicine (E1), Osaka University Graduate School of Medicine, 2-2 Yamada-oka, Suita City, Osaka 5650871, Japan (E-mail: hayashi@surg1.med. osaka-u.ac.jp).

J Thorac Cardiovasc Surg 2003;126: 1813-21

Copyright $\odot 2003$ by The American Association for Thoracic Surgery

$0022-5223 / 2003 \$ 30.00+0$

doi:10.1016/S0022-5223(03)01282-0
Objectives: This study was designed to examine the myocardial protective effect of leukocyte-depleted terminal blood cardioplegia in association with nitric oxide and peroxynitrite production, especially for patients undergoing prolonged aortic crossclamping.

Methods: Fifty-four patients ( 34 men, 20 women, mean age $56.7 \pm 12.7$ years) undergoing aortic valve replacement were randomly allocated to one of two groups; group LDTC $(\mathrm{n}=27)$ received 10 minutes of leukocyte-depleted terminal blood cardioplegic solution, and group CONT $(\mathrm{n}=27)$ served as controls. Each group was subdivided into 2 groups: aortic crossclamping for less than 120 minutes in groups LDTC-S ( $\mathrm{n}=13)$ and CONT-S $(\mathrm{n}=14)$; aortic crossclamping for 120 minutes or more in groups LDTC-L $(\mathrm{n}=14)$ and CONT-L $(\mathrm{n}=13)$.

Results: After aortic unclamping, group LDTC-L showed higher incidence of spontaneous defibrillation (78.6\% vs $30.8 \%, P=.0213$ ), higher plasma nitrate + nitrite in the coronary sinus effluent $(32.5 \pm 4.1 \mathrm{vs} 28.7 \pm 3.0 \mu \mathrm{mol} / \mathrm{L}, P=.0013)$, lower differences between coronary sinus effluent and arterial blood in the percentage ratio of nitrotyrosine to tyrosine (myocardium-derived peroxynitrite; 2.987\% \pm $0.576 \%$ vs $3.951 \% \pm 0.952 \%, P=.0036$ ), and plasma polymorphonuclear-elastase $(113.9 \pm 21.3$ vs $155.5 \pm 41.6 \mu \mathrm{g} / \mathrm{L}, P=.0029)$ and malondialdehyde $(2.75 \pm 0.67$ vs $4.02 \pm 0.96 \mu \mathrm{mol} / \mathrm{L}, P=.0005)$ than group CONT did. Postoperatively, group LDTC-L showed lower human-heart fatty acid-binding protein $(111.4 \pm 25.2 \mathrm{vs}$ $156.4 \pm 38.6 \mathrm{IU} / \mathrm{L}, P=.0013)$, lower creatine kinase-muscle and brain $(19.2 \pm 4.7$ vs $24.8 \pm 6.5 \mathrm{IU} / \mathrm{L}, P=.0120)$, and smaller requirement of catecholamine $(5.44 \pm$ $\left.2.29 \mathrm{vs} 8.45 \pm 3.42 \mu \mathrm{g} \cdot \mathrm{kg}^{-1} \cdot \min ^{-1}, P=.0122\right)$. There were no significant differences in these parameters between groups LDTC-S and CONT-S.

Conclusions: This study demonstrated that leukocyte-depleted terminal blood cardioplegia provided superior myocardial protective effects and regulated myocardialderived nitric oxide and peroxynitrite production only for patients undergoing aortic crossclamping for more than 120 minutes. The results suggest that prolonged aortic crossclamping deteriorates the tolerance to leukocyte-mediated myocardial injury accompanied by endothelial dysfunction associated with nitric oxide and peroxynitrite production. 


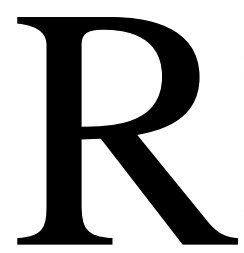

ecent advances in myocardial protection have lessened the chances of perioperative cardiogenic collapse and have provided satisfactory results associated with improved morbidity and mortality. Nevertheless, intraoperative myocardial dysfunction can occur in compromised hearts (such as severe left ventricular hypertrophied hearts or preoperative ischemic-injured hearts) because the tolerance to myocardial damage is deteriorated in such hearts. ${ }^{1,2}$ A long period of cardioplegic arrest is also a crucial factor that deteriorates the tolerance to perioperative myocardial injury., ${ }^{3,4}$ The mechanism of cardioplegic myocardial protection is based on the delay of the degradative process and the conservation of limited cellular energy, and thus, ischemic myocardial damage develops even under cardioplegic arrest. In addition, cardiopulmonary bypass (CPB) induces blood activation through the contact with artificial surfaces of the bypass circuit. ${ }^{5}$ An influx of CPB-induced chemotactic mediators to the coronary vessels around the reperfusion period can largely influence the severity of perioperative myocardial damage, and the production of cytotoxic mediators increases according to the duration of CPB involving cardioplegic arrest. ${ }^{5}$

Neutrophils are thought to play a pivotal role in the development of myocardial ischemia-reperfusion injury. ${ }^{6-9}$ Myocardial reperfusion after a period of ischemia induces a series of interactions between neutrophils and endothelial cells as follows: endothelial cell dysfunction, neutrophil adherence, myocardial infarction and apoptosis, and to some extent myocardial stunning. ${ }^{8}$ On the other hand, activated neutrophils themselves release cytotoxic chemotactic mediators, such as polymorphonuclear-elastase (PMNE), superoxide anion, myeloperoxidase, and proinflammatory cytokines. "Leukocyte depletion" has been suggested as a controlled myocardial reperfusion method, and we clinically demonstrated the efficacy of leukocyte-depleted terminal blood cardioplegia (LDTC) in the attenuation of perioperative myocardial injury especially for patients with a hypertrophied heart or a heart severely injured by preoperative ischemic insults. ${ }^{10,11}$ This modification around the reperfusion period can also be applicable to the cases requiring a long duration of aortic crossclamping (AXC).

Nitric oxide (NO) is an inflammation-mediated vasoactive substance and plays both cytoprotective and cytotoxic roles in the development of inflammation. ${ }^{12}$ Myocardium subjected to ischemia is reported to enhance NO production in the early phase. ${ }^{13,14}$ However, endogenous NO production decreases at myocardial reperfusion, which is thought to accelerate intraoperative myocardial damage. ${ }^{15-18}$ In clinical circumstances, CPB-activated neutrophils enhance myocardial endothelial damage and further reduces endogenous NO production. Therefore, LDTC appears to attenuate intraoperative endothelial damage associated with myo- cardial-derived $\mathrm{NO}$ and its related metabolites such as peroxynitrite $\left(\mathrm{ONOO}^{-}\right)$, which has not yet been elucidated. To examine the hypothesis that prolonged AXC participates in neutrophil-mediated deterioration of the tolerance to myocardial injury, we evaluated the myocardial protective effects of LDTC in reference to $\mathrm{NO}$ and $\mathrm{ONOO}^{-}$production for patients requiring prolonged $\mathrm{AXC}$.

\section{Methods and Materials}

\section{Study Population and Operative Procedures}

Fifty-four patients undergoing elective aortic valve replacement in our institution between 1997 and 2000 were enrolled in this study. Thirty-four were men and 20 were women, and their ages at operation ranged from 18 to 73 years with a mean of $56.7 \pm 12.7$ year. Twenty had aortic stenosis, 29 had aortic regurgitation, and 5 had both. Exclusion criteria was as follows: reoperation, concomitant mitral valve disease to be surgically treated, coronary artery disease requiring revascularization, and severe left ventricular hypertrophy shown as left ventricular mass index (LVMI) over $150 \mathrm{~g} / \mathrm{m}^{2}$ by echocardiography. None received nitroglycerin before, during, or after CPB for the duration of the study period. All patients gave their informed consent to participate in this study, and we followed the guidelines of our internal review board. The investigation conforms to the principles outlined in the Helsinki Declaration.

These patients were randomly divided into 2 groups; $10 \mathrm{~min}$ utes of LDTC was done followed by aortic unclamping in group LDTC $(\mathrm{n}=27)$. Group CONT $(\mathrm{n}=27)$ served as controls and terminal cardioplegia was not applied. Each group was subdivided into 2 groups according to AXC time (mean $126.1 \pm 31.2$ minutes). AXC time was under 120 minutes (AXC $<120$ minutes) in groups LDTC-S $(n=13)$ and CONT-S $(n=14)$ and was 120 minutes or more (AXC $\geq 120$ minutes) in groups LDTC-L ( $\mathrm{n}=$ 14) and CONT-L $(n=13)$.

Anesthesia was induced and maintained with diazepam, fentanyl, and inhaled isoflurane. Heparin at a dose of $3 \mathrm{mg} / \mathrm{kg}$ was infused, and CPB was instituted in a routine fashion. Two venous cannulas were placed directly into the superior vena cava and the inferior vena cava. An arterial cannula was positioned directly into the ascending aorta or the right subclavian artery. The CPB circuit was composed of a centrifugal pump, a membrane oxygenator, an arterial filter, a venous reservoir, and tubing lines, which were primed without blood components. No component of the CPB circuit was heparin-coated. CPB was controlled by $\alpha$-stat management with blood-flow rates of 2.2 to $2.6 \mathrm{~L} / \mathrm{min} / \mathrm{m}^{2}$ to maintain mean arterial pressure between 60 and $80 \mathrm{~mm} \mathrm{Hg}$, using vasoactive agents such as chlorpromazine hydrochloride and norepinephrine if necessary. We measured the temperature of blood in the arterial line just after it passed through the heat exchanger and controlled it at $34^{\circ} \mathrm{C}$. To reduce CPB-induced inflammatory response, 300,000 units of aprotinin (Trasylol; Bayer, Leverkusen, Germany) ${ }^{19}$ was added into venous reservoir at the initiation of CPB.

Intraoperative myocardial protection was achieved by initial and intermittent cold blood cardioplegia (BCP) administration, as previously described. ${ }^{20}$ Cardiac arrest was achieved by aortic crossclamping and an initial cold BCP administration (blood: 
crystalloid $=2: 1,16 \mathrm{mEq} / \mathrm{L}$ potassium and 0.8 to $1.0 \mathrm{mEq} / \mathrm{L}$ of calcium) at a volume of $3.0 \mathrm{~mL} / \mathrm{g}$ of left ventricular (LV) mass. Initial BCP was infused retrogradely into the coronary sinus until the aortotomy, at which point the remaining dose was infused in a selective antegrade fashion. A 4:1-blood:crystalloid BCP at a dose of $1.5 \mathrm{~mL} / \mathrm{g}$ of LV mass was infused every 20 minutes as an intermittent $\mathrm{BCP}$. The temperature of the BCP solution was maintained at $15^{\circ} \mathrm{C}$ to $20^{\circ} \mathrm{C}$. The myocardial temperature at the $\mathrm{LV}$ apex was monitored and maintained below $20^{\circ} \mathrm{C}$ by additional infusions of cardioplegic solution.

A leukocyte-removal filter (BC-1; Pall, East Hills, NY) was incorporated into the cardioplegic solution administration system just after the oxygenator reservoir for leukocyte depletion. ${ }^{21}$ For patients in group LDTC, leukocyte-depleted oxygenated blood was mixed with crystalloid cardioplegic solution (blood:crystalloid $=$ 4:1) and infused at a flow rate of $1.0 \mathrm{~mL} / \mathrm{min} / \mathrm{g}$ of LV mass with a perfusion pressure of less than $50 \mathrm{~mm} \mathrm{Hg}$ for 10 minutes. The LDTC temperature was set at $30^{\circ} \mathrm{C}$ at induction and was increased immediately to $36^{\circ} \mathrm{C}$. At the end of LDTC perfusion, the aorta was unclamped and the heart was reperfused with oxygenated whole blood in the conventional manner.

The patients were rewarmed after aortic unclamping, and CPB was terminated when rectal temperatures reached $35^{\circ} \mathrm{C}$. Subsequent administrations of catecholamine were performed as needed based on the patient's hemodynamic condition after the termination of CPB.

\section{Measurements}

In group LDTC, oxygenated blood for the cardioplegic solution was sampled just before aortic unclamping from both the inlet and outlet of the leukocyte-removal filter. To evaluate the efficiency of leukocyte depletion, leukocyte count and differential count for neutrophils were determined, and the depletion ratios were calculated.

Arterial blood (Ao) and coronary sinus effluent blood (CS) were obtained simultaneously before the initiation of CPB and at 5 minutes after aortic unclamping. Plasma PMNE levels were measured using enzyme immunoassay to evaluate the degree of neutrophil activation. Plasma PMNE in Ao was considered CPBinduced neutrophil activation, and the difference in plasma PMNE between CS and Ao (CS-Ao difference in PMNE) was considered reperfusion-induced neutrophil activation. Plasma nitrate + nitrite (NOx), major end products of NO, were measured as a marker of NO production by the method based on the Griess reaction. Plasma levels of nitrotyrosine and tyrosine were measured using a highpressure liquid chromatography (HPLC) method. The percentage ratio of nitrotyrosine to tyrosine ([nitrotyrosine/(tyrosine + nitrotyrosine) $\times 100 \%$; $\left.\% \mathrm{NO}_{2}-\mathrm{Tyr}\right)$ was considered $\mathrm{ONOO}^{-}$production, and the difference in $\% \mathrm{NO}_{2}$-Tyr between CS and Ao (CS-Ao difference in $\% \mathrm{NO}_{2}$-Tyr) was used as an index of myocardiumderived $\mathrm{ONOO}^{-}{ }^{22}$ Plasma levels of malondialdehyde (MDA) were measured using the ion-pairing HPLC method, and the difference between CS and Ao (CS-Ao difference in MDA) was used as an index of myocardial lipid peroxidation mediated by oxygen radicals.

The rate of spontaneous defibrillation and the maximum dose of catecholamine (dopamine plus dobutamine) during the postoperative period were used as clinical parameters to evaluate myo- cardial protective effects. The CS-Ao difference in PMNE, CS-Ao difference in MDA, plasma human-heart fatty acid-binding protein (HH-FABP), and peak plasma creatine kinase-muscle and brain (peak CK-MB) were used as biochemical indicators of perioperative myocardial damage after cardiac surgical procedures. $^{20,21}$ Plasma HH-FABP was measured at 45 minutes after myocardial reperfusion using a sandwich enzyme immunoassay. Plasma CK-MB was measured every 6 hours after operation using immunoinhibition assay, and the maximum value during the first 24 postoperative hours was used as peak CK-MB.

\section{Statistical Analysis}

All data are expressed as mean \pm standard deviation (SD). Statistical correlations were indicated by Pearson correlation coefficient test and simple regression analysis. Chi-square test for independence, one-factor analysis of variance, and unpaired Student $t$ test were used to compare values between the groups. All analyses were performed with the Statview v5.0 statistical package (Abacus Concepts Inc, Berkeley, Calif). A $P$ value of less than .05 was considered statistically significant.

\section{Results}

\section{Patient Characteristics and Clinical Outcomes}

There were no significant differences in the patient data such as age at operation, sex, body weight, body surface area, LVMI, aortic valvular disease, concomitant aortic disease, CPB time, and AXC time between groups CONT-S and LDTC-S and between groups CONT-L and LDTC-L (Table 1).

All patients in this study tolerated the surgical procedures and were discharged without any complications related to cardioplegic solution administration. Perioperative myocardial infarction was not observed in either group, and no cardiogenic shock requiring circulatory assist device occurred. There was no mortality, and none fell into cardiac failure late after hospital discharge.

\section{Depletion Efficiency of Leukocytes and Neutrophils}

At the end of LDTC reperfusion, the efficiency of leukocyte depletion was $94.6 \% \pm 2.4 \%$ and that of neutrophil depletion was $93.5 \% \pm 1.9 \%$.

\section{Correlation between AXC Time and Plasma PMNE in the Arterial Blood}

Plasma PMNE level in Ao was significantly correlated with AXC time in overall patients $(r=.913, P<.0001$; Figure $1, a)$. There was no significant difference in plasma PMNE between groups CONT-S and LDTC-S (CONT-S vs LDTC-S: $574.5 \pm 77.3$ vs $565.0 \pm 69.8 \mu \mathrm{g} / \mathrm{L}, P=.7411)$ and between groups CONT-L and LDTC-L (CONT-L vs LDTC-L: $813.5 \pm 83.8$ vs $785.5 \pm 107.9 \mu \mathrm{g} / \mathrm{L}, P=.4601$; Figure 1,b).

Plasma NOx in Ao and CS (before CPB and after AXC) Plasma NOx before CPB did not differ significantly between Ao and CS in each group ([Ao vs CS] CONT-S: 27.3 

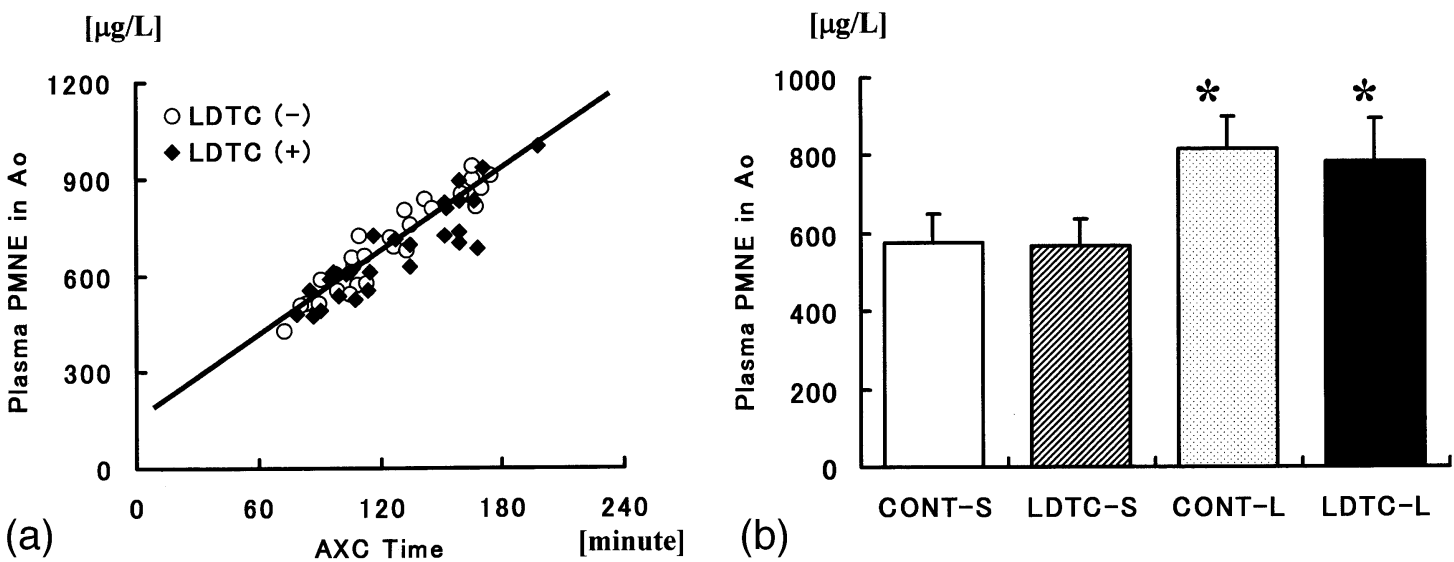

Figure 1. a, Relation between the aortic crossclamping time (AXC time) and plasma level of polymorphonuclearelastase in the arterial blood (PMNE in Ao) (PMNE in Ao $=156.189+4.189 \times$ AXC time; $R^{2}=.834$ ). b, Comparisons of PMNE in Ao among the 4 groups. Data are expressed as mean \pm SD. ${ }^{*} P<.0001$ vs CONT-S or LDTC-S.

TABLE 1. Patient characteristics and cardiopulmonary bypass data (mean \pm SD)

\begin{tabular}{|c|c|c|c|c|}
\hline & $\begin{array}{l}\text { Group CONT-S } \\
\quad(n=14)\end{array}$ & $\begin{array}{l}\text { Group LDTC-S } \\
\quad(\mathbf{n}=\mathbf{1 3})\end{array}$ & $\begin{array}{l}\text { Group CONT-L } \\
\quad(n=13)\end{array}$ & $\begin{array}{l}\text { Group LDTC-L } \\
\quad(n=14)\end{array}$ \\
\hline Age (years) & $53.9 \pm 11.6$ & $54.8 \pm 12.2$ & $57.4 \pm 17.4$ & $60.6 \pm 9.1$ \\
\hline Sex (men/women) & $8 / 6$ & $10 / 3$ & $8 / 5$ & $8 / 6$ \\
\hline Body weight (kg) & $59.2 \pm 15.2$ & $63.6 \pm 17.1$ & $53.7 \pm 10.2$ & $55.3 \pm 13.3$ \\
\hline Body surface area $\left(\mathrm{m}^{2}\right)$ & $1.64 \pm 0.24$ & $1.65 \pm 0.25$ & $1.57 \pm 0.21$ & $1.56 \pm 0.20$ \\
\hline Left ventricular mass index $\left(\mathrm{g} / \mathrm{m}^{2}\right)$ & $119.2 \pm 12.7$ & $122.9 \pm 13.9$ & $125.6 \pm 18.7$ & $127.1 \pm 11.3$ \\
\hline \multicolumn{5}{|l|}{ Aortic valvular disease } \\
\hline Aortic stenosis & 2 & 3 & 7 & 8 \\
\hline Aortic regurgitation & 11 & 9 & 4 & 5 \\
\hline Aortic stenosis and regurgitation & 1 & 1 & 2 & 1 \\
\hline \multicolumn{5}{|l|}{ Concomitant aortic disease } \\
\hline Annulo-aortic ectasia & 0 & 0 & 1 & 1 \\
\hline Aneurysm of the ascending aorta & 1 & 1 & 1 & 1 \\
\hline Cardiopulmonary bypass time (minutes) & $135.5 \pm 14.5$ & $137.7 \pm 16.4$ & $184.1 \pm 15.4^{*}, \dagger$ & $191.6 \pm 16.7^{*}, \dagger$ \\
\hline Aortic crossclamping time (minutes) & $98.4 \pm 12.7$ & $99.7 \pm 12.1$ & $149.3 \pm 18.0^{*}, \dagger$ & $156.7 \pm 17.5^{*}, \dagger$ \\
\hline
\end{tabular}

${ }^{*} P<.01$ vs group CONT-S.

$\dagger P<.01$ vs group LDTC-S.

\pm 2.9 vs $27.5 \pm 2.7 \mu \mathrm{mol} / \mathrm{L}, P=.8517 ;$ LDTC-S: $26.4 \pm$ 2.5 vs $27.3 \pm 2.0 \mu \mathrm{mol} / \mathrm{L}, P=.4358$; CONT-L: $26.4 \pm 3.0$ vs $26.9 \pm 3.3 \mu \mathrm{mol} / \mathrm{L}, P=.6896$; LDTC-L: $27.5 \pm 3.2$ vs $26.6 \pm 2.7 \mu \mathrm{mol} / \mathrm{L}, P=.4285)$. Five minutes after aortic unclamping, plasma NOx in CS was significantly lower than that in Ao in all groups ([CS vs Ao] CONT-S: $32.3 \pm$ 4.1 vs $30.4 \pm 3.2 \mu \mathrm{mol} / \mathrm{L}, P=.0183$; LDTC-S: $33.6 \pm 4.8$ vs $31.5 \pm 4.0 \mu \mathrm{mol} / \mathrm{L}, P=.0237$; CONT-L: $35.2 \pm 4.5$ vs $28.7 \pm 3.0 \mu \mathrm{mol} / \mathrm{L}, P=.0001$; LDTC-L: $35.6 \pm 5.1 \mathrm{vs}$ $32.5 \pm 4.1 \mu \mathrm{mol} / \mathrm{L}, P=.0088)$. Plasma NOx levels in both Ao and CS were significantly higher after reperfusion than before ischemia in all groups $(P<.0001$ in each group). Plasma NOx in CS after reperfusion was significantly higher in group LDTC-L $(32.5 \pm 4.1 \mu \mathrm{mol} / \mathrm{L})$ than in group CONT-L $(28.7 \pm 3.0 \mu \mathrm{mol} / \mathrm{L}, P=.0013)$, whereas there was no significant difference between groups LDTC-S (31.5 $\pm 4.0 \mu \mathrm{mol} / \mathrm{L})$ and CONT-S $(30.4 \pm 3.2 \mu \mathrm{mol} / \mathrm{L}, P=$ .4358; Figure 2).

\% $\mathrm{NO}_{2}$-Tyr in Ao and CS (before CPB and after AXC) Nitrotyrosine was not detected in the supernatant of either sample obtained before CPB. Five minutes after aortic unclamping in all groups, it was detected in both samples of Ao and CS, and $\% \mathrm{NO}_{2}$-Tyr in CS was significantly higher than that in Ao $(P<.0001$ in each group). Group LDTC-L showed a significantly lower $\% \mathrm{NO}_{2}$-Tyr in CS $(3.35 \% \pm$ $0.65 \%$ vs $4.18 \% \pm 0.77 \%, P=.0055)$ and a significantly lower CS-Ao difference in $\% \mathrm{NO}_{2}$ - $\mathrm{Tyr}(2.987 \% \pm 0.576 \%$ vs $3.951 \% \pm 0.952 \%, P=.0036$ ) than group CONT-L did, whereas there were no significant differences in $\% \mathrm{NO}_{2}-\mathrm{Tyr}$ 


\section{$[\mu \mathrm{mol} / \mathrm{L}]$}

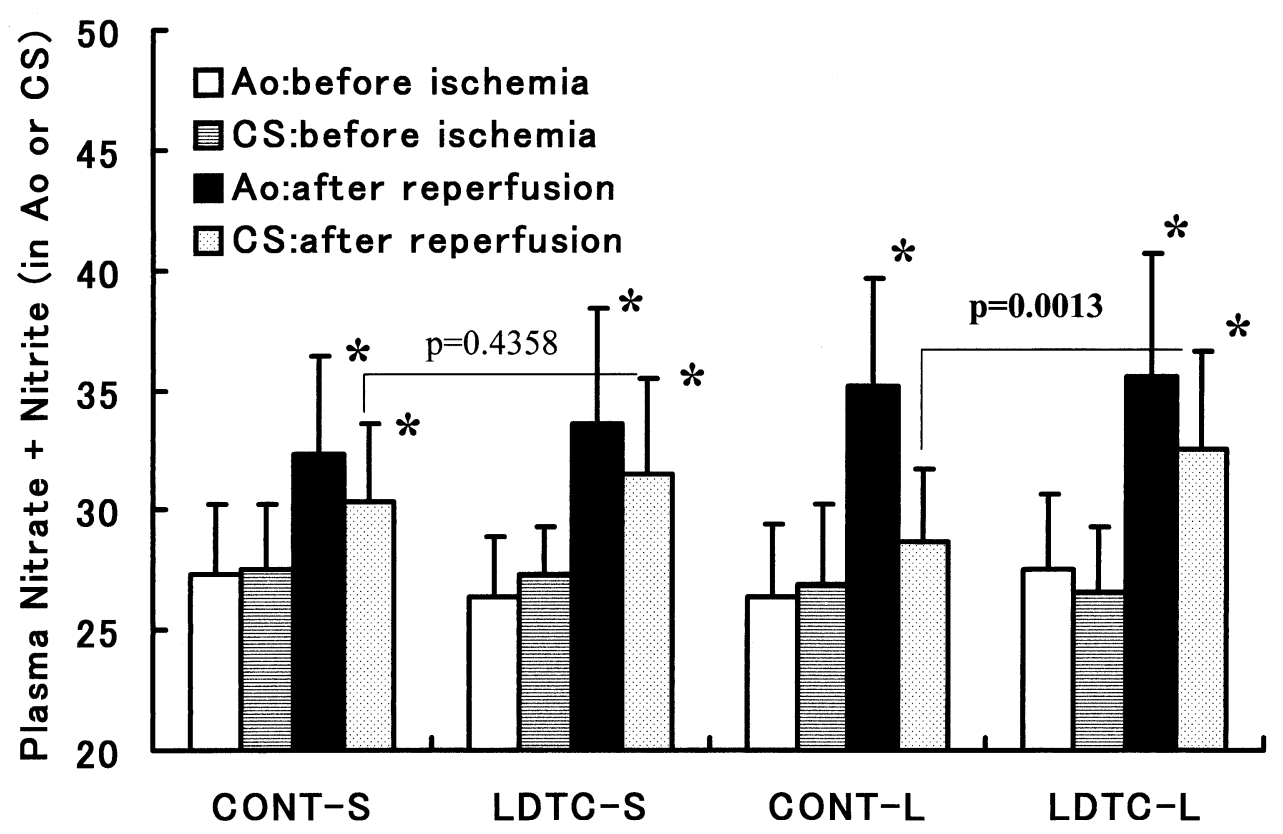

Figure 2. Changes in the plasma levels nitrate + nitrite (NOx) in the blood obtained from aortic root and coronary sinus, before cardiopulmonary bypass and 5 minutes after aortic unclamping. Data are expressed as mean \pm SD. ${ }^{*} \boldsymbol{P}<.0001$ vs Ao before ischemia or CS before ischemia.

in CS $(2.31 \% \pm 0.45 \%$ vs $2.56 \% \pm 0.56 \%, P=.1347)$ and CS-Ao difference in $\% \mathrm{NO}_{2}$-Tyr $(1.785 \% \pm 0.127 \%$ vs $2.001 \% \pm 0.558 \%, P=.1077)$ between groups LDTC-S and CONT-S (Figure 2, b, and Figure 3). The CS-Ao difference in $\% \mathrm{NO}_{2}$-Tyr was significantly correlated with AXC time (group LDTC: $r=.899, P<.0001$; group CONT: $r=.933, P<.0001)$ and the CS-Ao difference in PMNE (group LDTC: $r=.893, P<.0001$; group CONT: $r=.820, P<.0001 ;$ Figure 4$)$.

\section{Clinical and Biochemical Parameters Associated with} Myocardial Protection

The percentage ratio of patients with spontaneous defibrillation after aortic unclamping was significantly higher and the maximum catecholamine dose during the postoperative period was significantly smaller in group LDTC-L than in group CONT-L. There were no significant differences in these parameters between groups LDTC-S and CONT-S (Table 2).

Five minutes after aortic unclamping, group LDTC-L showed significantly smaller CS-Ao difference in PMNE $(113.9 \pm 21.3$ vs $155.5 \pm 41.6 \mu \mathrm{g} / \mathrm{L}, P=.0029)$, CS-Ao difference in MDA $(2.75 \pm 0.67$ vs $4.02 \pm 0.96 \mu \mathrm{mol} / \mathrm{L}, P$ $=.0005)$, HH-FABP $(111.4 \pm 25.2$ vs $156.4 \pm 38.6 \mathrm{IU} / \mathrm{L}$, $P=.0013)$, and peak CK-MB $(19.2 \pm 4.7$ vs $24.8 \pm 6.5$
IU/L, $P=.0120)$ than group CONT-L. Between groups LDTC-S and CONT-S, however, there were no significant differences in these parameters (PMNE: $83.8 \pm 16.1$ vs 96.5 $\pm 26.5 \mu \mathrm{g} / \mathrm{L}, P=.1472$; MDA: $1.51 \pm 0.43$ vs $1.95 \pm 0.86$ $\mu \mathrm{mol} / \mathrm{L}, P=.2462$; HH-FABP: $82.3 \pm 16.8$ vs $95.2 \pm 23.8$ $\mathrm{IU} / \mathrm{L}, P=.1187$; CK-MB: $12.0 \pm 3.1$ vs $13.1 \pm 4.2 \mathrm{IU} / \mathrm{L}$, $P=.4263 ;$ Figure 5).

\section{Discussion}

In this clinical study, LDTC-treated patients with AXC of 120 minutes or more showed a significantly higher percentage of spontaneous defibrillation after aortic unclamping, lower CS-Ao differences in PMNE and MDA after reperfusion, lower postoperative HH-FABP and peak CK-MB, and smaller dosage of catecholamine requirement than LDTC-untreated patients with AXC of 120 minutes or more. As for NO production, plasma NOx level in CS was significantly higher and the CS-Ao difference in $\% \mathrm{NO}_{2}$-Tyr was significantly lower in the LDTC-treated patients with AXC of 120 minutes or more than in the LDTC-untreated patients with AXC of 120 minutes or more. On the other hand, significant differences in these above parameters were not observed between the LDTC-treated and LDTC-untreated patients undergoing AXC for less than 120 minutes. 
[\%]

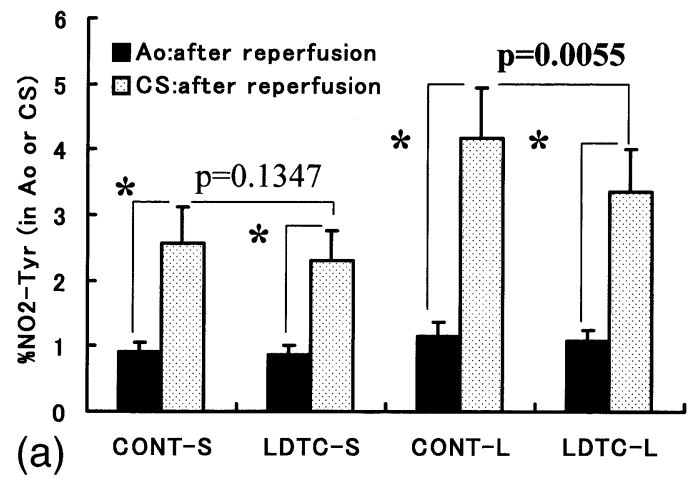

[\%]

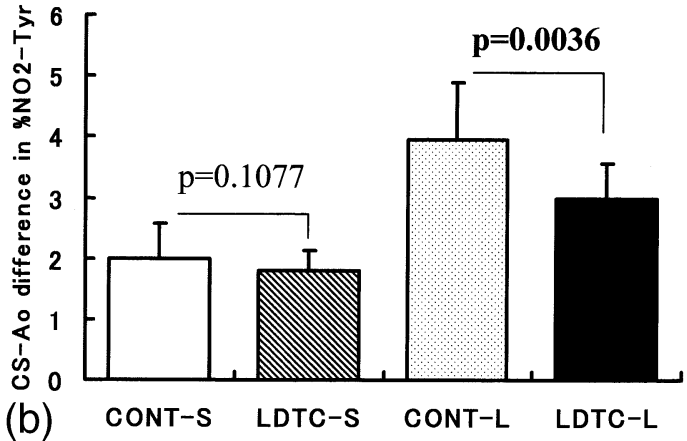

Figure 3. a, Changes in the percentage ratio of plasma nitrotyrosine to tyrosine $\left(\% \mathrm{NO}_{2}-\mathrm{Tyr}\right)$ in the blood obtained from aortic root $(A O)$ and coronary sinus $(C S)$, before cardiopulmonary bypass and 5 minutes after aortic unclamping. Data are expressed as mean \pm SD. ${ }^{*} P<.0001 ;$ Ao vs CS after reperfusion. $b$, Comparisons of the difference in $\% \mathrm{NO}_{2}$-Tyr between coronary sinus effluent and arterial blood (CS-Ao in $\% \mathrm{NO}_{2}$-Tyr) 5 minutes after aortic unclamping. Data are expressed as mean \pm SD.

[\%]

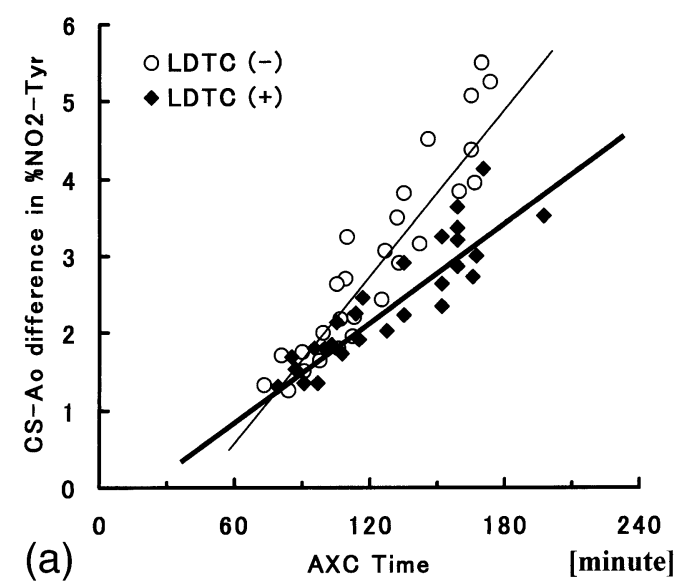

[\%]

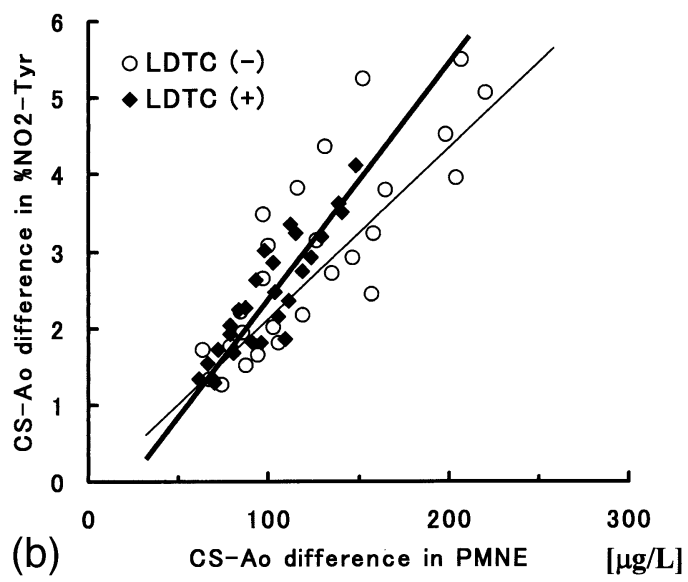

Figure 4. Relations between (a) the aortic crossclamping time (AXC time) and the difference in the percentage ratio of plasma nitrotyrosine to tyrosine between coronary sinus effluent and arterial blood (CS-Ao in \% $\mathrm{NO}_{2}-\mathrm{Tyr}$ ) 5 minutes after aortic unclamping. Group LDTC: CS-Ao in $\% \mathrm{NO}_{2}-\mathrm{Tyr}=-0.351+0.021 \times \mathrm{AXC}$ time $\left(R^{2}=.809\right)$; group CONT (LDTC $(-)$ ): CS-Ao in $\% \mathrm{NO}_{2}-\mathrm{Tyr}=1.834+0.039 \times$ AXC time $\left(R^{2}=.871\right)$. Relations between (b) CS-Ao in $\% \mathrm{NO}_{2}$-Tyr and the difference in the plasma levels of polymorphonuclear-elastase (CS-Ao difference in PMNE) 5 minutes after aortic unclamping. Group LDTC: CS-Ao difference in $\%_{N_{2}}-\mathrm{Tyr}=0.441+0.029 \times$ CS-Ao difference in PMNE ( $\left.R^{2}=.798\right)$; group CONT (LDTC $\left.(-)\right)$ : CS-Ao difference in $\% \mathrm{NO}_{2}$-Tyr $=0.116+0.023 \times$ [CS-Ao difference in PMNE $\left.\left(R^{2}=.672\right)\right]$.

Regarding neutrophil activation during reperfusion, arachidonate cascade and xanthine-xanthine oxidase system are thought to play pathophysiologically crucial roles in the development of myocardial ischemia-reperfusion injury. ${ }^{23,24}$ The activation of arachidonate cascade induces the release of various chemotropism substances, which activate circulating neutrophils during reperfusion. ${ }^{24} \mathrm{~A}$ large amount of free radicals produced from myocardium at reperfusion through xanthine-xanthine oxidase system also activates circulating neutrophils. ${ }^{23}$ Prolonged AXC further activates arachidonate cascade and xanthine-xanthine oxidase system, which enhances CPB-induced neutrophil activation. Therefore, the duration of cardioplegic arrest largely affects the severity of neutrophil-mediated intraoperative myocar- 

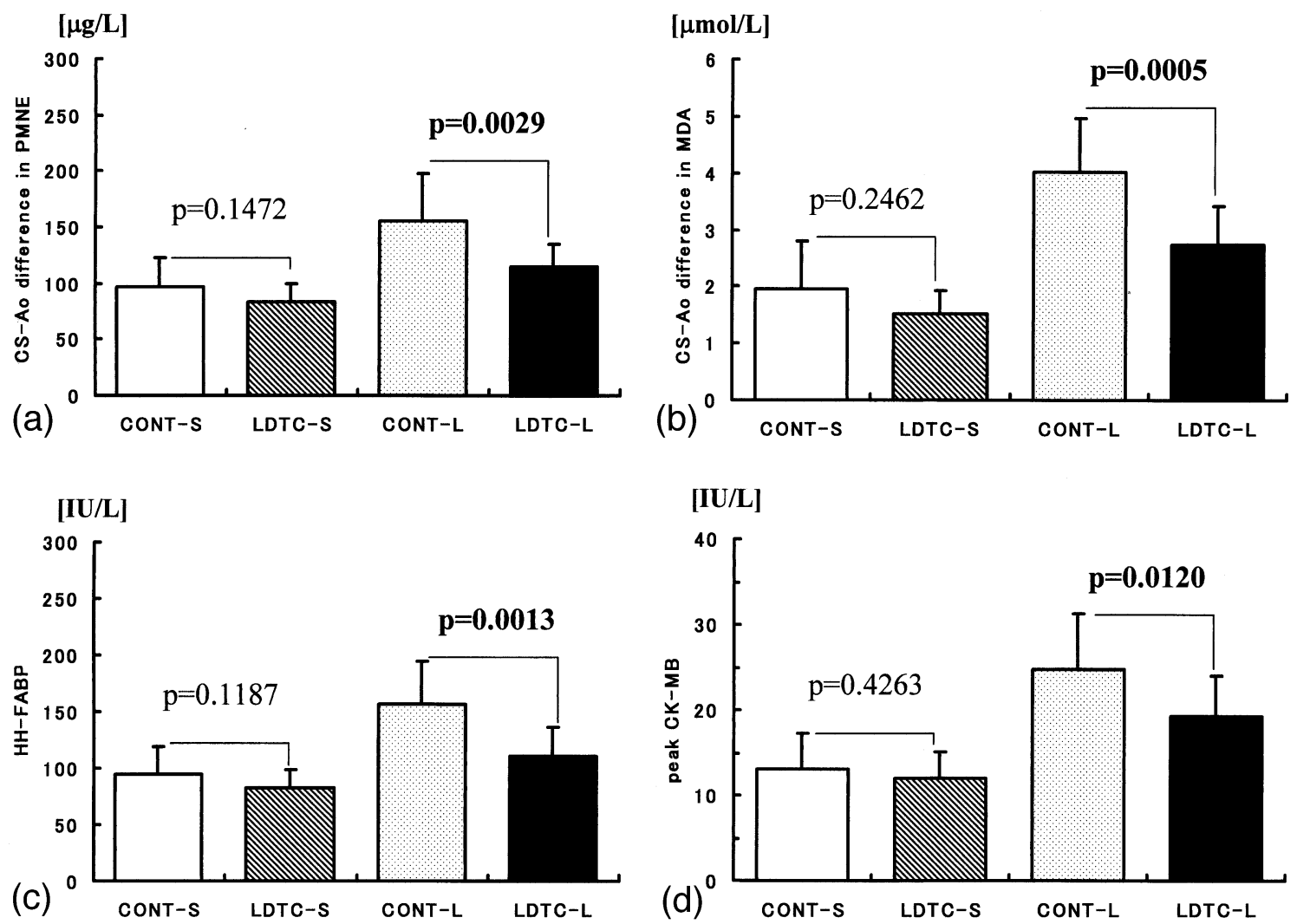

Figure 5. Comparisons of (a) the difference in plasma polymorphonuclear-elastase between coronary sinus effluent and arterial blood 5 minutes after aortic unclamping (CS-Ao difference in PMNE); (b) the difference in plasma malondialdehyde between coronary sinus effluent and arterial blood 5 minutes after aortic unclamping (CS-Ao difference in MDA); (c) plasma human-heart fatty acid-binding protein in the arterial blood 45 minutes after aortic unclamping (HH-FABP); and (d) peak plasma creatine kinase-muscle and brain during the first 24 postoperative hours (peak $C K-M B)$. Data are expressed as mean \pm SD.

TABLE 2. Clinical parameters associated with myocardial protection

\begin{tabular}{|c|c|c|c|c|c|c|}
\hline & $\begin{array}{c}\text { Group CONT-S } \\
(n=14)\end{array}$ & $\begin{array}{c}\text { Group LDTC-S } \\
(\mathrm{n}=13)\end{array}$ & $P$ value & $\begin{array}{l}\text { Group CONT-L } \\
(n=13)\end{array}$ & $\begin{array}{l}\text { Group LDTC-L } \\
(\mathrm{n}=14)\end{array}$ & $P$ value \\
\hline $\begin{array}{l}\text { Percentage ratio of spontaneous } \\
\text { defibrillation after aortic } \\
\text { unclamping }(\%)\end{array}$ & 78.6 & 84.6 & $>.9999$ & 30.8 & 78.6 & .0213 \\
\hline $\begin{array}{l}\text { Maximum dose of catecholamine } \\
\text { required during the postoperative } \\
\text { period }(\mu \mathrm{g} / \mathrm{kg} / \mathrm{min})\end{array}$ & $3.18 \pm 1.42$ & $3.41 \pm 2.04$ & .7361 & $8.45 \pm 3.42$ & $5.44 \pm 2.29$ & .0122 \\
\hline
\end{tabular}

dial damage, and our results are consistent with the pathophysiology of the development of myocardial ischemiareperfusion injury.

Leukocyte depletion during myocardial reperfusion attenuates inflammatory responses mediated by the interaction between neutrophils and coronary endothelial cells and activated by neutrophil-produced chemotactic mediators. ${ }^{6-9}$ In this study, activated neutrophils were normothermically perfused into the coronary vessels after aortic unclamping in both groups. However, terminal cardioplegia is a kind of warm blood perfusion even though infused to nonworking hearts with cardioplegic arresting vehicles, and it is considered as a "warm-up" perfusion prior to aortic unclamping by the acceleration of myocardial metabolic recovery and the preservation of high-energy phosphate..$^{25,26}$ In addition, the first 10 minutes of reperfusion are the most critical period 
for intraoperative myocardial protection. ${ }^{27-29}$ The major morphological changes of subcellular levels are detected in this period. ${ }^{27}$ Intracellular neutrophil hydrogen peroxide begins to increase as early as 15 minutes, ${ }^{29}$ and Tsao and colleagues $^{28}$ demonstrated that peak free radical production and subsequent endothelial damage occurred very early after myocardial reperfusion. Regarding this pathophysiological aspect, it is rational that leukocyte depletion during terminal cardioplegia attenuated intraoperative myocardial damage induced by subsequent reperfusion with activated neutrophils.

The change in NO production during cardiac surgery is considered an adaptive response to maintain systemic homeostasis against myocardial ischemia and CPB-induced inflammation, which is regulated by 2 kinds of NO synthase (NOS) ${ }^{30,31}$ In the early period after CPB initiation or AXC, endothelial-constitutive NOS (ecNOS) is activated to enhance endogenous NO production. ${ }^{30}$ In the late period, ecNOS activity is gradually impaired and subsequent inducible NOS (iNOS) expression compensates for the reduction in endogenous NO production. ${ }^{31,32}$ However, abrupt myocardial deterioration at reperfusion enhances the impairment of ecNOS activity, ${ }^{15-17}$ resulting in the marked difference in NOx in CS as shown in this study. Furthermore, the result that plasma NOx was significantly higher in LDTC-treated patients with AXC of 120 minutes or more supports the hypothesis that intraoperative neutrophil activation is largely associated with the impairment of ecNOS activity of coronary endothelial cells.

NO derived from endothelium rapidly reacts and combines with superoxide anion to form $\mathrm{ONOO}^{-}$. On the other hand, superoxide anion is released by endothelium and neutrophils through the activation of NADH oxidase. Therefore, a reduction in neutrophil activation and subsequent reduction in superoxide anion contributes to reduce the production of potentially cytotoxic $\mathrm{ONOO}^{-}$. This study demonstrates that LDTC reduces neutrophil activation and subsequent myocardium-derived $\mathrm{ONOO}^{-}$production in patients requiring prolonged AXC.

Although the cytotoxicity of $\mathrm{ONOO}^{-}$is considered much greater than that of other free radicals, ${ }^{33-35}$ recent experimental studies have demonstrated that $\mathrm{ONOO}^{-}$plays a cytoprotective role in the development of intraoperative myocardial ischemia-reperfusion injury. ${ }^{36-38}$ Plasma $\mathrm{ONOO}^{-}$level only suggests the amount of superoxide production and the degree of myocardial injury at present. Further elucidations are needed to clarify the role of $\mathrm{ONOO}^{-}$in the development of myocardial ischemia-reperfusion injury under clinical circumstances.

In summary, we first demonstrated the myocardial protective effects of LDTC in association with NO and $\mathrm{ONOO}^{-}$production. This study has clearly demonstrated that LDTC provides superior myocardial protective effects and regulates myocardium-derived $\mathrm{NO}$ and $\mathrm{ONOO}^{-}$production only for patients undergoing more than 120 minutes of AXC. These results suggest that prolonged AXC deteriorates the tolerance to neutrophil-mediated myocardial injury accompanied by endothelial dysfunction associated with $\mathrm{NO}$ and $\mathrm{ONOO}^{-}$production.

\section{References}

1. Rosenkranz ER, Vinten-Johansen J, Buckberg GD, Okamoto F, Edwards H, Bugyi H. Benefits of normothermic induction of blood cardioplegia in energy-depleted hearts, with maintenance of arrest by multidose cold blood cardioplegic infusions. J Thorac Cardiovasc Surg. 1982;84:667-77.

2. Warner KG, Khuri SF, Kloner RA, et al. Structural and metabolic correlates of cell injury in the hypertrophied myocardium during valve replacement. J Thorac Cardiovasc Surg. 1987;93:741-54.

3. Chambers DJ, Darracott-Cankovic S, Braimbridge MV. Clinical and quantitative birefringence assessment of 100 patients with aortic clamping periods in excess of 120 minutes after hypothermic cardioplegic arrest. Thorac Cardiovasc Surg. 1983;31:266-72.

4. Bar-El Y, Adler Z, Kophit A, et al. Myocardial protection in operations requiring more than $2 \mathrm{~h}$ of aortic cross-clamping. Eur J Cardiothorac Surg. 1999; 15:271-5.

5. Downing SW, Edmunds LH Jr. Release of vasoactive substances during cardiopulmonary bypass. Ann Thorac Surg. 1992;54:1236-43.

6. Engler RL, Dahlgren MD, Peterson MA, Dobbs A, Schmid-Schonbein GW. Accumulation of polymorphonuclear leukocytes during 3-h experimental myocardial ischemia. Am J Physiol. 1986;251:H93-100.

7. Forman MB, Puett DW, Virmani R. Endothelial and myocardial injury during ischemia and reperfusion: pathogenesis and therapeutic implications. J Am Coll Cardiol. 1989;13:450-9.

8. Boyle EM Jr, Pohlman TH, Cornejo CJ, Verrier ED. Endothelial cell injury in cardiovascular surgery: ischemia-reperfusion. Ann Thorac Surg. 1996;62:1868-75.

9. Zahler S, Massoudy P, Hartl H, Hahnel C, Meisner H, Becker BF. Acute cardiac inflammatory responses to postichemic reperfusion during cardiopulmonary bypass. Cardiovasc Res. 1999;41:722-30.

10. Sawa Y, Matsuda H, Shimazaki Y, et al. Evaluation of leukocytedepleted terminal blood cardioplegic solution in patients undergoing elective and emergency coronary artery bypass grafting. J Thorac Cardiovasc Surg. 1994;108:1125-31.

11. Sawa Y, Taniguchi K, Kadoba K, et al. Leukocyte depletion attenuates reperfusion injury in patients with left ventricular hypertrophy. Circulation. 1996;93:1640-6.

12. Moncada S, Palmer RM, Higgs EA. Nitric oxide. Physiology, pathophysiology and pharmacology. Pharmacol Rev. 1991;43:109-42.

13. Node K, Kitakaze M, Kosaka H, et al. Plasma nitric oxide end products are increased in the ischemic canine heart. Biochem Biophys Res Commun. 1995;211:370-4.

14. Node K, Kitakaze M, Sato $\mathrm{H}$, et al. Increased release of nitric oxide in ischemic hearts after exercise in patients with effort angina. J Am Coll Cardiol. 1998;32:63-8.

15. Ma X-L, Weyrich AS, Lefer DJ, Lefer AM. Diminished basal nitric oxide release after myocardial ischemia and reperfusion promotes neutrophil adherence to coronary endothelium. Circ Res. 1993;72:40312.

16. Fukuda H, Sawa Y, Kadoba K, Taniguchi K, Shimazaki Y, Matsuda H. Supplement of nitric oxide attenuates neutrophil-mediated reperfusion injury. Circulation. 1995;92(Suppl II):II413-6.

17. Engelman DT, Watanabe M, Engelman RM, et al. Constitutive nitric oxide release is impaired after ischemia and reperfusion. J Thorac Cardiovasc Surg. 1995;110:1047-53.

18. Gohra H, Fujimura Y, Hamano K, et al. Nitric oxide release from coronary vasculature before, during and following cardioplegic arrest. World J Surg. 1999;23:1249-53.

19. Seghaye MC, Duchateau J, Grabitz RG, et al. Influence of low-dose aprotinin on the inflammatory reaction due to cardiopulmonary bypass in children. Ann Thorac Surg. 1996;61:1205-11. 
20. Hayashi Y, Sawa Y, Ohtake S, Nishimura M, Ichikawa H, Matsuda H. Controlled nicorandil administration for myocardial protection during coronary artery bypass grafting under cardiopulmonary bypass. J Cardiovasc Pharmacol. 2001;38:21-8.

21. Hayashi Y, Sawa Y, Nishimura M, et al. Clinical evaluation of leukocyte-depleted blood cardioplegia for pediatric open heart operation. Ann Thorac Surg. 2000;69:1914-9.

22. Hayashi Y, Sawa Y, Ohtake S, Fukuyama N, Nakazawa H, Matsuda H. Peroxynitrite formation from human myocardium after ischemia-reperfusion during open heart operation. Ann Thorac Surg. 2001;72:571-6.

23. Chambers DE, Parks DA, Patterson G, et al. Xanthine oxidase as a source of free radical damage in myocardial ischemia. $\mathrm{J} \mathrm{Mol} \mathrm{Cell}$ Cardiol. 1985;17:145-52.

24. Bagchi D, Wetscher GJ, Bagchi M, et al. Interrelationship between cellular calcium homeostasis and free radical generation in myocardial reperfusion injury. Chem Biol Interact. 1997;104:65-85.

25. Teoh KH, Christakis GT, Weisel RD, et al. Accelerated myocardial metabolic recovery with terminal warm blood cardioplegia. J Thorac Cardiovasc Surg. 1986;91:888-95.

26. Nomura F, Forbess JM, Mayer EJ. Effects of hot shot on recovery after hypothermic ischemia in neonatal lamb heart. J Cardiovasc Surg. 2001;42:1-7.

27. Schaper J, Schaper W. Reperfusion of ischemic myocardium: ultrastructural and histochemical aspects. J Am Coll Cardiol. 1983;1:1037-46.

28. Tsao PS, Lefer AM. Time course and mechanism of endothelial dysfunction in isolated ischemic-and hypoxic-perfused rat hearts. Am J Physiol. 1990;259:H1660-6.

29. Ko W, Hawes AS, Lazenby WD, et al. Myocardial reperfusion injury: platelet-activating factor stimulates polymorphonuclear leukocyte hydrogen peroxide production during myocardial reperfusion. J Thorac Cardiovasc Surg. 1991;102:297-308.
30. Ruvolo G, Greco E, Speziale G, et al. Nitric oxide formation during cardiopulmonary bypass. Ann Thorac Surg. 1994;57:1055-7.

31. Ungureanu-Longrois D, Balligand JL, Kelly RA, Smith TW. Myocardial contractile dysfunction in the systemic inflammatory response syndrome: role of a cytokine-inducible nitric oxide synthase in cardiac myocytes. J Mol Cell Cardiol. 1995;27:155-67.

32. Koglin J, Glysing-Jensen T, Mudgett JS, Russell ME. Exacerbated transplant arteriosclerosis in inducible nitric oxide-deficient mice. Circulation. 1998;97:2059-65.

33. Beckman JS, Beckman TW, Chen J, Marshall PA, Freeman BA. Apparent hydroxyl radical production by peroxynitrite: implications for endothelial injury from nitric oxide and superoxide. Proc Natl Acad Sci U S A. 1990;87:1620-4.

34. Ishida H, Ichimori K, Hirota Y, Fukahori M, Nakazawa H. Peroxynitrite-induced cardiac myocyte injury. Free Radic Biol Med. 1996;20: 343-50.

35. Landino LM, Crews BC, Timmons MD, Morrow JD, Marnett LJ. Peroxynitrite, the coupling product of nitric oxide and superoxide, activates prostaglandin biosynthesis. Proc Natl Acad Sci USA. 1996;93:15069-74.

36. Lefer DJ, Scalia R, Campbell B, et al. Peroxynitrite inhibits leukocyteendothelial cell interactions and protects against ischemia-reperfusion injury in rats. J Clin Invest. 1997;99:684-91.

37. Nossuli TO, Hayward R, Jensen D, Scalia R, Lefer AM. Mechanisms of cardioprotection by peroxynitrite in myocardial ischemia and reperfusion injury. Am J Physiol. 1998;275(2 Pt 2):H509-19.

38. Ronson RS, Thourani VH, Ma X-L, et al. Peroxynitrite, the breakdown product of nitric oxide, is beneficial in blood cardioplegia but injurious in crystalloid cardioplegia. Circulation. 1999;100(Suppl II):II38491. 